\title{
Two 3D Virtual Worlds as Domain-Oriented Design Environments: Closing the Educational Gap with the Action-Breakdown-Repair Model
}

\author{
Anders I. Mørch \\ Department of Education, University of Oslo, Norway \\ Email: anders.morch@iped.uio.no
}

Purpose: The present study proposes action-breakdown-repair (ABR) as a pedagogical model, and 3D virtual worlds as technology, to bridge the gap between curricular goals and students out of school technology experiences, referred to as the educational gap.

Approach. A qualitative study combining design-based research and a case study was used with video observation as data collection method. ABR is demonstrated by an empirical analysis of learning activities with (OMinecraft (hereafter MC) and (C)Second Life ${ }^{\mathrm{TM}}$ (hereafter SL)

used in two teacher education programs.

Findings: Teachers and students could use the technology with some initial training. Experience in gameplay, collaboration, and problem solving eased the transitioning into curricular activities. The teachers integrated domain knowledge by giving students tasks that involved the creation of domain-specific artifacts and roleplay scenarios. Two dilemmas of educational gap closing were found and discussed: learning domain knowledge vs. learning technology, and breakdown in action vs. breakdown in understanding.

Originality: A novelty of the present research is treating ABR as a pedagogical model and closing the educational gap.

Practical implications: The model can provide guidance for teachers and other stakeholders who are in the process of integrating creative technologies like visual programming, design environments, and collaboration tools, in K-12 education. Research implications: Automated feedback (critiquing) adapted to students' individual needs while building and roleplaying in MC or SL to off load some of the teachers' work in scaffolding design activities in the classroom is a direction for further work.

\section{Introduction}

The editors of this special issue called for articles that address the themes of "Rethinking and Reinventing Learning, Education, and Collaboration: From Creating Technologies to Transforming Cultures." This article aims to contribute to transforming educational culture by proposing action-breakdown-repair (ABR) as a pedagogical model for technology use in education. ABR originated in the fields of design and human-computer interaction (Ehn, 1988; Fischer, 1994b; Schön, 1983) as a three-step process. First, the designers (here, a group of learners) create domainspecific artifacts (action). The design activity stops when the designers encounter a problem (breakdown). Then, to continue, the designers must repair the breakdown, providing opportunities for learning. ABR is demonstrated with an empirical analysis of learning activities in two virtual worlds (CMinecraft and $\left(\right.$ Second Life ${ }^{\mathrm{TM}}$ ) used in two teacher education programs. MC is also a digital game, but we used a version of 
the game (Education Edition) in Creative mode, which means all the gaming elements were turned off; enabling a focus on design in learning activity.

The rationale for ABR is to create a bridge between two types of learning, school learning (formal) and out-of-school learning (practical) that in the outset is discontinuous, according to (Resnick, 1987). She used examples from mathematics to show this phenomenon and argued that schools need to focus on thinking and learning abilities as educational goals to motivate children for school learning and make the distinctions between formal and practical less sharp. In particular, she suggested that people need to learn to recognize and deal with breakdowns, such as unfamiliar problems, to temporarily work around them, repair them, and ultimately, design better systems (Resnick, 1987). We refer to teachers' activities for bridging between learning in and out of school as closing the educational gap, and we focus on two approaches toward that end, generic skills and educational use of popular technologies.

Educational researchers have proposed a distinction between the practice of generic (21st century, soft) and domain-specific skills (Binkley et al., 2012; Resnick, 2017; Schaaf and Mohan, 2014). Domain-specific skills are associated with a specific subject area taught in school (e.g., math, English, chemistry, social studies). Generic skills are domain-general and apply across several subjects; these skills include communication, collaboration, problem solving, visualization, creativity, learning to learn, computational thinking, and other elements (Binkley et al., 2012; Resnick, 2017; Schaaf and Mohan, 2014). Generic and domain-specific skills are closely related. For example, visualization is used in mathematics and chemistry, and communication is required for language learning. When specific subjects are taught, generic skills are often taken for granted. In today's multicultural society with greater variety in children's backgrounds and interests, and with the computer as a common denominator, strategies for developing integrated learning environments are appearing, that is, combining domain-specific and generic skills practice in the same digital environment.

Two popular technologies used in many schools today are Scratch (Resnick et al., 2009) and Knowledge Forum (Bereiter and Scardamalia, 2003). The starting points for learning with these technologies are children's everyday experiences in play and inquiry, respectively. Scratch is a block-based visual programming language and website where children create games and animations by assembling code blocks analogous to building a Lego house. Scratch was mainly developed for practicing outof-school soft skills (Resnick, 2017), but has become a popular technology used in many classrooms around the world to learn coding. Knowledge Forum is a collaborative learning environment where students develop domain knowledge by asking questions (e.g., questions about an observed natural science phenomenon, such as the weather) and developing scientific understanding through a gradual clarification process, e.g., towards average weather and the climate. Scratch and Knowledge Forum differ in terms of technology focus and learner behavior (creating games and animations vs. shared knowledge), but they complement each other in interesting ways. For example, if the Scratch collaborative online community was organized as a knowledge-building community, curriculum-driven and interest-driven learning could be realized in the same digital learning environment. 
Some 30 years ago, Gerhard Fischer and his students at the University of Colorado, Boulder, proposed the seeds (proof of concept) of such a technology, referred to as a domain-oriented design environment (DODE; Fischer, 1994a). One early DODE was Janus (Fischer et al., 1989; Fischer and Girgensohn, 1990). Fischer and colleagues (1993) defined design as the creative act of making artifacts while being informed about design principles obtained from domain knowledge. We use a similar meaning in this article, but we also use design as a research method (see the Methods section). The five components of a DODE are as follows: 1) The main user interface is a construction kit consisting of a set of domain-specific building blocks (design units) used to create more complex visual artifacts. 2) A critiquing component analyses partial designs to identify patterns of relations among the design units according to the design rules. The aim of critiquing is to trigger a shift from action to reflection (Fischer et al., 1989). 3) All components of a DODE are seeded with domain knowledge before instantiation (Fischer, 1994a; Fischer et al., 1989). 4) Design units and rules are modifiable by end users with tailoring tools (Fischer and Girgensohn, 1990). 5) The DODE framework and the prototypes were inspired by Schön's (1983) theory of reflection-in-action.

Over the past eight years, we have revigorated the idea of domain-oriented design environments, and seeded two three-dimensional (3D) virtual worlds MC and SL) with domain knowledge. We chose these technologies because they are used by many people and offer educators new possibilities to design learning experiences, which would not be possible in a traditional classroom (Dieterle and Clarke, 2007). Our preliminary observation and literature studies revealed that an educational gap prevails in many schools today. Therefore, we ask the following research question: How to bridge the gap between the practice of generic ("out of school") and domainspecific ("in school") skills with the ABR model with two 3D virtual worlds?

The rest of the paper is organized as follows. First, we present a survey of previous work of using SL and MC in and out of school. Then, we present the theory of the ABR model, followed by our research methods and data collection. Next, we discuss the results of two empirical studies and compare the results with findings reported in the literature. At the end, we summarize our findings, and suggest some directions for further work.

\section{Two 3D virtual worlds in the practice of generic and domain-specific skills}

Generic skills are practiced first outside school (taught by parents and peers), whereas domain-specific skills are taught mainly by teachers. Over time, these practices become intertwined to achieve higher levels of competence. Previous researchers have shown that MC and SL can support both types of skill practice, but there are also challenges.

Research indicates that 3D virtual worlds can be integrated into a teacher education program to provide preservice teachers with the experiences needed to apply teaching skills in real school settings (Caruso et al., 2014; Muir et al., 2013). Virtual worlds allow students to engage in social interaction, collaboration, and conflict resolution at a distance (Vasileiou and Paraskeva, 2010; Muir et al., 2013). Gregory and Masters (2012) argued that virtual role-playing can enhance the theoretical component of 
preservice education. Their results showed that although students prefer the real-life version of the learning activity, they find virtual role-playing easier than face-to-face meetings, because in the virtual world people are presented as avatars and feel more comfortable (e.g., less self-conscious) to act out a role.

The Norwegian Media Authority (2020) rated MC one of the most popular digital game among 9 to 18-year-old children. However, teachers' perception of $\mathrm{MC}$ as a game and not a tool for learning raises some concerns. A survey of education and experimental research studies found that the tool's technological and pedagogical affordances (e.g., visualization of scientific concepts) support a broad range of domain-specific skills, including mathematics, chemistry, computer science, and social studies (Nebel et al., 2016). A case study that explored the use of MC in a high school literature class (Cipollone, 2014), which included making films based on plots created in the game world, found that the tool also offers a unique opportunity for students to display their creativity and understanding of concepts in ways that are more feasible than if they were attempted in the "real" world. In another study, a challenge was found when students were attaining 21 st-century skills with Minecraft. The teacher played a considerable role (Callaghan, 2016). In a study with MC in a teacher education program, Mørch, Eie \& Mifsud (2018) found that student teachers perceive the use of $\mathrm{MC}$ in their teaching as a possible threat to domain-specific knowledge, but they also consider generic skills such as design and collaboration as a new way of reaching their students. A recent meta-study of 28 articles showed that $\mathrm{MC}$ can support domain-specific skills (science, math, social sciences, and language classes) and generic skills (engagement, interest, and enthusiasm), but identified three challenges: lack of focused learning objectives, inflexible curriculum, and no previous gaming skills (Baek et al., 2020).

\section{Reflection-in-action and the action-breakdown-repair model}

The ABR model is an operationalization of Donald Schön's theory of reflection-inaction (Ehn, 1988; Fischer 1994; Schön, 1983; Winograd and Flores, 1986), which suggests that people toggle between action and reflection by thinking about alternatives and what to do next when they create. In Schön's (1983, p. 280) own words, "doing and thinking are complementary. Doing extends thinking in the test, moves, and probes of experimental action, and reflection feeds on doing and its results. Each feeds the other, and each sets boundaries for the other."

Schön (1983, p. 68) did not use the terms breakdown and repair but described the transition between action and reflection in the following way: "[ $\mathrm{t}]$ he practitioner allows himself to experience surprise, puzzlement, or confusion in a situation, which he finds uncertain or unique." In other words, a breakdown can be associated with a unique or uncertain situation, and repair is about transitioning from the state of uncertainty into a potential learning situation. Ehn $(1988$, p. 66) extended Schön's work to participatory design, adopting terminology from Winograd and Flores (1986) and explaining the connection between breakdown and knowledge as follows: "[b]reakdown of understanding of a well-known situation is at the same time the opening to new knowledge and eventually an understanding of something new." In addition to a breakdown in understanding (Ehn, 1988; Fischer et al., 1989), Fischer and Girgensohn (1990) identified breakdown in technology, and Stahl (1993) breakdown in action. 
Fischer and colleagues (Fischer, 1994a; Fischer et al., 1989; Fischer and Girgensohn, 1990; Stahl, 1993) developed computer support for the ABR model and Schön's theory of reflection-in-action using DODEs. Breakdowns became associated with broken design rules or the failure to achieve desired relations among design units according to domain knowledge. A demonstration system for kitchen design (Janus) implemented this as automated feedback (critique) when design rules were not achieved in a specific design. Repair in a DODE was accomplished by new actions (moving design units), modifying design units and rules using end-user development tools (Fischer and Girgensohn, 1990) and improving designers' understanding using online access to knowledge (Fischer et al., 1989; Stahl, 1993). In the present study, the ABR model is used as an analytical framework.

\section{Research design and methods Research design}

A 3D virtual world is different from virtual reality (VR) and augmented reality (AR) in that the 3D virtual world requires no head gear (e.g., 3D glasses). It resembles a digital game but without gaming elements such as survival and competition. After crossing a low digital competency threshold, individuals can interact with people and objects as avatars (Figure 1). A virtual world compares with the toy worlds young children create to play together in and out of the house in terms of open-ended problems, collaboration, and creativity. Virtual worlds provide support for creative activities, such as building complex visual structures (Mørch et al., 2018), and engaging students in virtual roleplaying (Mørch, Mifsud \& Eie, 2019).
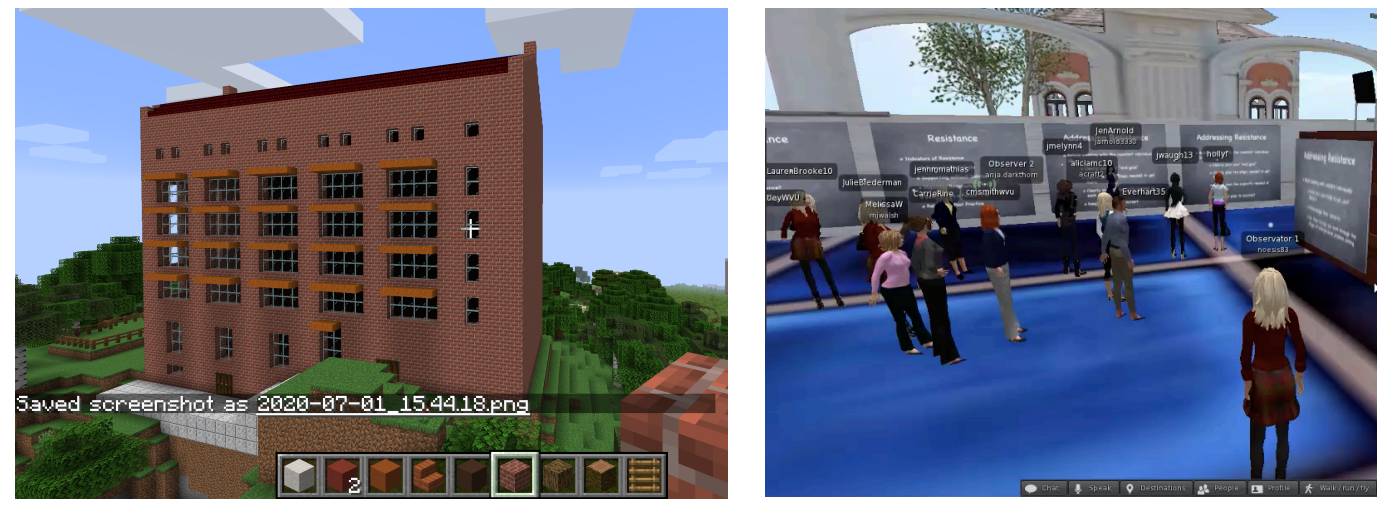

Figure 1: In $\odot$ Minecraft (left) and $\odot$ Second Life ${ }^{\mathrm{TM}}$ (right) users appear as avatars in a virtual 3D world of graphical objects with which the users can interact and build with and use for play and learning activities.

In this study, MC and SL were seeded with domain knowledge in the following ways: SL has served as a virtual college campus for a distance education graduate program in special education (Figure 1, right) at a southern university in the United States (Caruso et al., 2014, Mørch, Caruso \& Hartley, 2017; Mørch et al., 2018). The MC world (Figure 1, left) was seeded with a virtual river representing Aker River in City and sites for the reconstruction of historical buildings based on an assignment given to undergraduate teacher education students studying to be social studies teachers in Country (Mørch, Eie \& Mifsud, 2018; Mørch, Mifsud \& Eie, 2019).

\section{Participants and data collection}


Thirty-four in-service (full time working) teachers took part in the SL distance education master's program, participating in seven live two-hour class sessions and nine collaborative group work sessions spanning four weeks. Each class consisted of a combination of teacher-led and student-centered activities, including interactive lectures on theoretical concepts (30 minutes), individual activities (15 minutes), group activities in separate rooms (30 minutes), and role-playing activities (10 minutes). Learning was embedded within the activities, and members of the group were assigned roles during the sessions. We used a qualitative research approach, combining a case study and virtual ethnography (Boellstorff et al., 2012).

The MC study followed design-based research (DBR) principles (Hoadley, 2002). Sixty second-year undergraduate student teachers participated in the study over a three-week period to solve an assignment to reconstruct various historical buildings. They were also to create a role-play connected to the building, illustrating, for example, the working and living conditions during the historical period.

In both studies, we collected observation data automatically with screen capture software. Next, we thematically categorized the data, according to an open coding (data-driven) iterative classification process, partly informed (top-down) by the research question. Inspired by interaction analysis (Jordan and Henderson, 1995) we focused on the participants' verbal interactions (chat and voice) mediated by the technology, reproduced as data excerpts below. All names used are pseudonyms.

\section{Data and analysis}

The following examples and extracts from the video data demonstrate learning opportunities with the two virtual worlds: 1) scaffolding by the instructor, 2) searching for domain knowledge, and 3) end-user development (customization and programming). The examples are organized into three subsections, partly informed by ABR: 1) context, 2) data, and 3) analysis (action, breakdown, and repair). The data consists of visual and verbal extracts of screen capture video. The examples were chosen for illustrative purposes and are drawn from the two studies. The full analysis has been omitted for space reasons.

\section{Example 1: Scaffolding in a virtual world: Finding a lost group member with the instructor's help}

\section{Context}

In complex learning environments, such as SL, incorporating technology into assignments ensures that students practice the skills necessary to participate in the class sessions. The basic skills to be demonstrated in a virtual 3D world include the ability to fly, teleport, speak, landmark a location, send a friend request, and buy materials from a box (such as the box on the table in Figure 2). The group shown in Figure 2 consisted of six persons, but only five were present. The two persons standing to the right were the session coordinators. The instructor entered the room as the conversation captured in Figure 2 began.

Data 


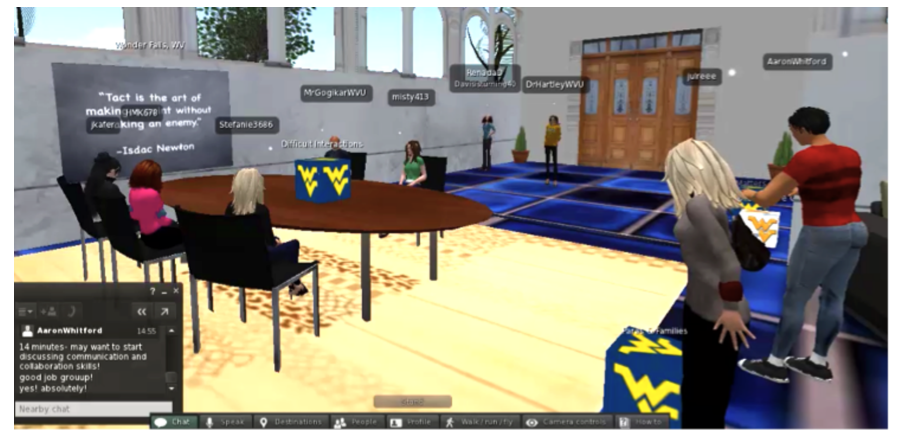

Laura: That is why I do not fly; I walk or run. [Laughs] OK, I think she's coming.

John: [to instructor], if one of our people is flying around lost, tell them that $[\ldots]$ is there a way that we can get them to come here? Student \#6 seems to be a little lost.

Instructor: Oh yeah, I can - I can help. You said Student \#6 is lost?

John: Yes, Student \#6

Instructor: $\mathrm{OK}$, let me look on the mini-map. Oh, I found her; I'll bring her over. I'll be right back [Instructor flies away].

Figure 2: A group session in (CSecond Life ${ }^{\mathrm{TM}}$ to develop a role-playing scenario. One person is missing, and the instructor provides scaffolding to find the person.

Analysis

1. Action: A group of students was ready to start working on their group assignment (creating a script for a role-play), but the last person had not yet arrived.

2. Breakdown: The missing student was lost in the virtual world and could not find the meeting room.

3. Repair: The instructor received a request for assistance from John and used a SL tool called a mini-map, a virtual world geography map of logged-in users. The instructor demonstrated the tool for the students and found the missing student.

\section{Example 2: Searching for domain knowledge while playing: Detailing windows in building reconstruction}

\section{Context}

Before the social studies teacher education students started the assignment in MC, they attended a lecture and site visit about the impact of the Industrial Revolution on City. Each group was assigned the task to reconstruct an historical building and act out a role-play about class struggle and exploitation. During the building reconstruction, the students discussed the shape, color, and placement of the windows (Figure 3). In the accompanying discussion reproduced in Table 1, two participants (Alexandra and Dennis) made a design decision.

\section{Data}
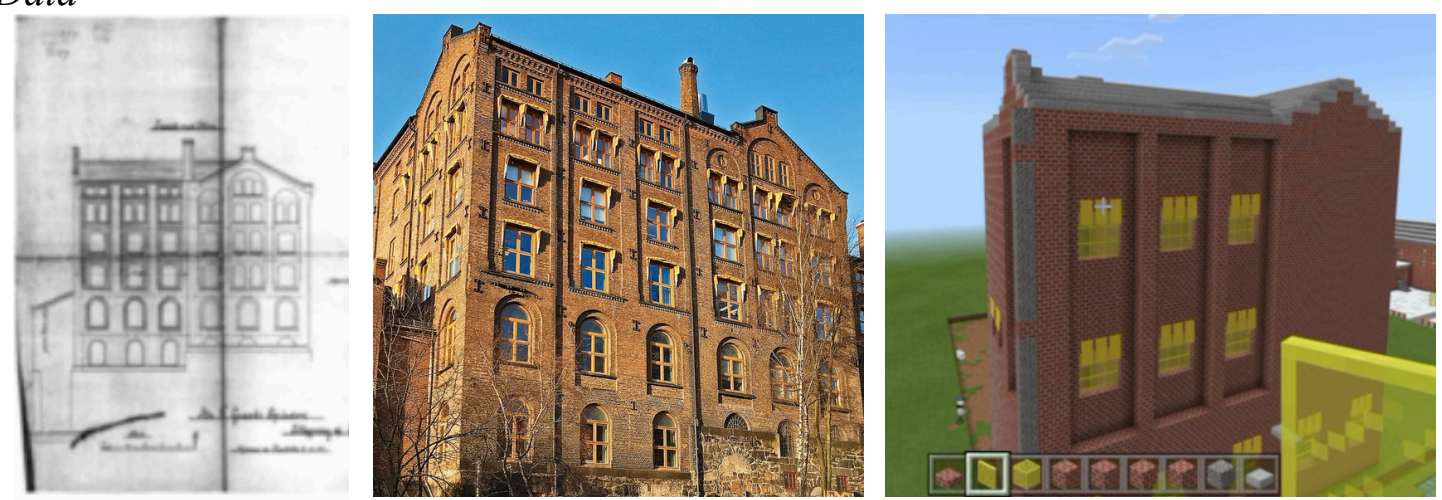

Figure 3: Left: An architectural drawing the group used as a model when starting to build, Middle: a current picture of the building, and Right: the building created by the group in (CMinecraft.

Table 1. Two students are discussing the color of windows to be used in the MC building.

Speaker Utterance

Actions/comments 
Alexandra Yes, but I think we should have yellow windows since the windows are yellow.

Dennis Should we have yellow windows?

Alexandra Yes, I know it is ugly, but that is what is shown in the picture.

Dennis
By looking at the architectural drawing in Figure 3, the group members could not know the color of the windows and found a current picture with yellow color from an internet search.

Dennis asks in an unsure voice, as he wondered if she meant yellow windows or something else. They chose yellow windows to achieve the best approximation of the real building.

Dennis searched in the MC building block inventory and found yellow windows.

Analysis

1. Action: The students had been building together for about 50 minutes without any major disruptions before they entered the situation described in which they were trying to figure out how to create windows in MC based on the building blocks in their inventory and the historical drawing of the building on their laptop.

2. Breakdown: The students were unsure how to make arched windows and what color they should be.

3. Repair: By searching on the internet for a recent picture (the middle image in Figure 3), they found that the windowsills and blinds were yellow. They did not solve the arched window problem and ended up with rectangular windows with yellow-tinted glass to approximate the real-world building.

\section{Example 3: End-user development in a virtual world: Customizing a box for information sharing \\ Context}

In this example from SL, in-service special education teachers were working in small groups on an assignment to create a role-play for another group to act out. After creating the scenario, they had to write instructions on a notecard for the other group and put the notecard in a box for sharing information. As the conversation captured in Figure 4 began, the group was ready to create their box.

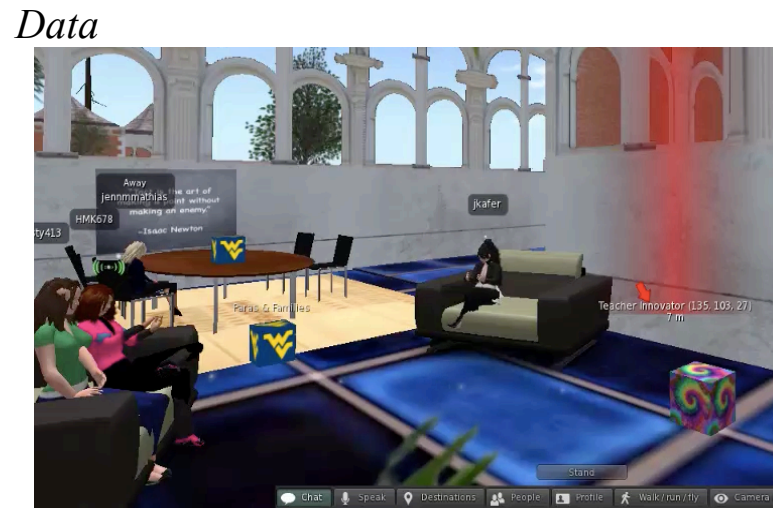

Stacy: OK, now we need somebody to make the box. Heather: Y'all go together and do that [...] can we build it in here? [A default box appears on the screen in yellow.] Stacy: I'm not sure if we can or not.

Heather: I think we can build it here [in the group room], we just have to put it in our inventory before we leave. I have one $[. .$.$] started; I'll try to get it so you can see it. [Typing]$ Janet: Exactly.

Stacy: Ok. [The box color changes several times]

Heather: That's a fancy box. Is it changing: the scenery on it or are you changing that?

Mandy: [Positive tone of voice] Yeah, can you see it? Heather: Yeah, I can [laughs]

Mandy: OK, tell me when you we get something you like.

Figure 4: The participants in the four-person group collaborate to customize an information-sharing box (the fancy colored cube in the lower right-hand corner of the image).

Analysis

1. Action: The students had been using information-sharing boxes to share a roleplaying script with another group and to read the course materials provided by the 
instructor. In this activity, the students were asked by the instructor to create a new box.

2. Breakdown: The group decided to customize the box to fit their group identity (i.e., make it different from the other boxes), but Stacy was unsure whether they could do it collaboratively or if one of them had to do it and share the results.

3. Repair: The box eventually appeared in the room in a default state based on Heather's actions ("I have one [...] started; I'll try to get it so you can see it."). She believed it could be shared and saved in her building block inventory. Then, Mandy modified the box into the pattern shown in Figure 4. When the group figured out how to make changes that were visible to all, it gave them great pleasure, which is evident in the tone of their interactions (Mørch, Caruso \& Hartley, 2017).

\section{Example 4: End-user development in a virtual word: Enhancing the game experience through programming \\ Context}

A shift from action to repair with programming can be initiated by an assignment. We offer a hypothetical example. Imagine students are asked to reconstruct a building in MC using two techniques: partly hands-on and partly using the tool's builder agent (an automated tool controlled by end-user development). To accomplish this, one student must write a program in MakeCode (a block-based language) or JavaScript (a textual language), such as the one shown in Figure 5, which involves the looping construct, a key concept in programming.

\section{Data}

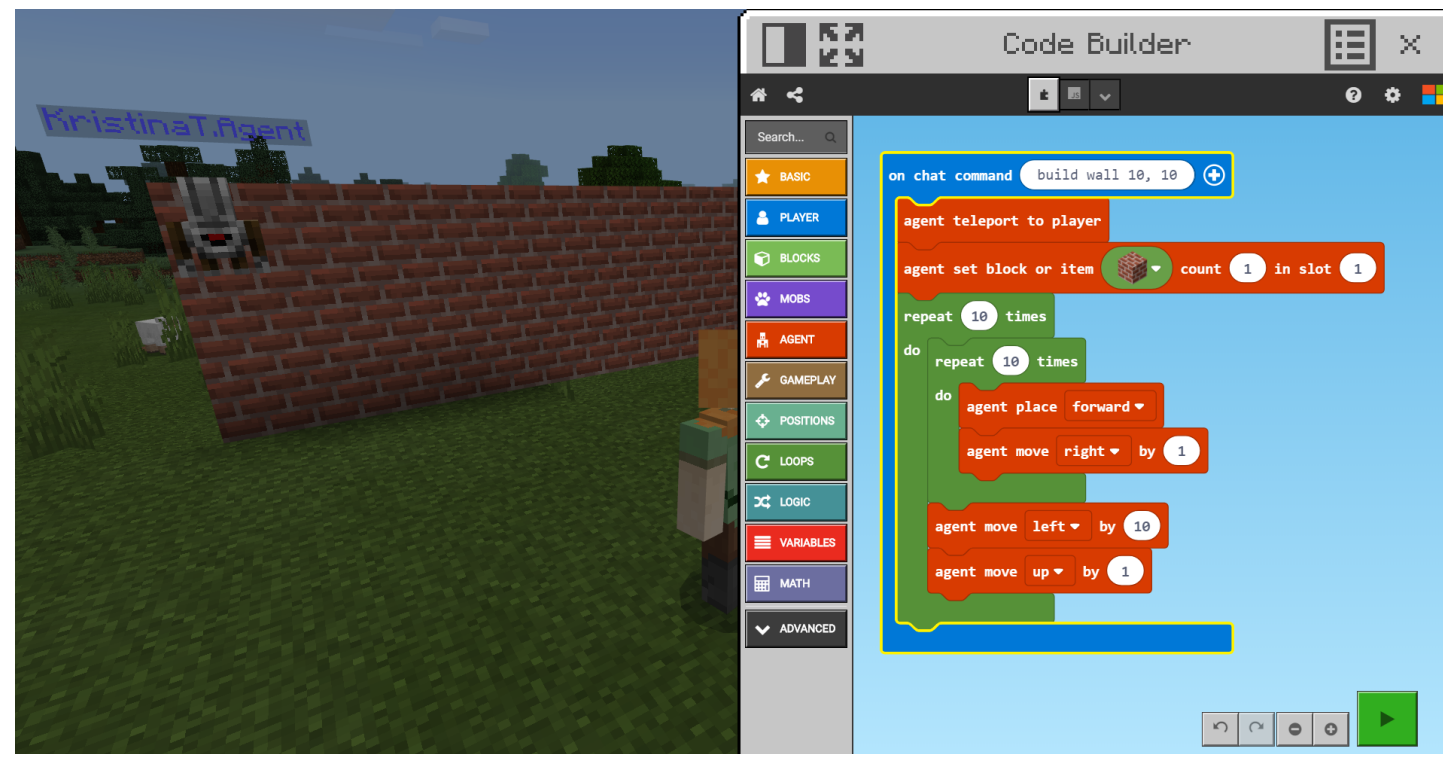

Figure 5: @Minecraft screen image with game window (left) and Code Builder (right). Typing "C" in the game window opens the builder. When the code is executed, the builder agent creates a $10 \times 10$ wall, brick by brick, using two loops with one (nested) inside the other.

Analysis

1. Action: In this hypothetical situation, students work together to reconstruct a realworld (historical) building. The activity is engaging but non-reflective; it is a continuous flow of movement, social talk, and building block actions (choose, place, and break) once the basic commands are mastered. 
2. Breakdown: The assignment asks the learners to create a program to automate part of the building process, which requires switching to Code Builder, a more abstract mode of working in $\mathrm{MC}$, by typing " $\mathrm{C}$ " in the game window.

3. Repair: The process of creating the program code introduces students to a key concept in computer science, the looping construct. The students can toggle between a block-based language (MakeCode) and JavaScript to solve the problem.

\section{Results and discussion}

This article addresses the question of bridging the gap between generic ("out of school") and domain-specific ("in school") skills' practices with the ABR model with two virtual worlds. Both teachers and students could use the two technologies with some initial training. Experience in gameplay, collaboration, and problem solving eased the transitioning into curricular activities. The teachers integrated domain knowledge by giving students tasks that involved the creation of domain-specific artifacts and roleplay scenarios. Two dilemmas summarize the findings: learning domain knowledge vs. learning technology, and breakdown in action vs. breakdown in understanding.

\section{Learning domain knowledge vs. learning technology}

Of the four examples shown above, two illustrate learning to use technology (SL) and two illustrate learning domain knowledge (the social studies topic pertaining to the Industrial Revolution and the looping construct used in computer science in MC). The fourth example shows how a social studies topic and a computer science concept can be learned simultaneously. During the learning activities, the students received an introductory lecture and access to domain knowledge, which were a textbook in special education and an online user manual in the SL case, and historical material about life and work during the Industrial Revolution in City in the MC case.

The students did not report a lack of domain knowledge, but the analysis (e.g., Example 2) indicated they sometimes passed over material too quickly. The ABR model starts with an open-ended design process (Schön, 1983) interrupted by breakdowns at uneven intervals in shifting the focus of attention from action to reflection (Ehn, 1988; Fischer et al., 1989; Winograd and Flores, 1986). From a pedagogical perspective, the teacher acts as a design critic who helps students gradually align with disciplinary norms through scaffolding, bringing a degree of objectivity to the highly subjective directives of the students' creative design process, including keeping time. The focus shift was observed and analyzed using social science methods, e.g., observation protocols, interaction analysis (Jordan and Henderson, 1995), and theories of shared understanding (Stahl, 1993), such as adopting scientific concepts in conversation that gradually replace everyday concepts (Mørch et al., 2019; Lemke, 1990; Vygotsky, 1986). The findings thus far (the MC project is ongoing) indicate that the observed students need more scaffolding or more time to practice on their own to create artifacts that are sufficiently knowledge based, as some of the students took shortcuts and ended up with suboptimal solutions (see Example 2). Perhaps breakdowns must be signaled more often and partly automated, as the teachers are not always available to help students in the formative process of building shared understanding. For example, a critiquing mechanism that automatically signals when a learning activity is subpar with respect to the use of domain-specific knowledge. Another solution would be to (re)seed the virtual worlds for use in a specific domain (e.g., Chemistry Update introduces a chemistry resource 
pack to MC). These suggestions are resonant with the ideas put forth in the conceptual framework of domain-oriented design environments (Fischer, 1994a).

\section{Breakdown in action vs. breakdown in understanding}

The switch from breakdown to repair can be initiated by students (see Examples 2 and 3 ) or by the teacher (directly, as in the interaction in Example 1, or indirectly, as in the assignment in Example 4). The switch gives students access to tools they can use to redirect their work and incorporate more domain knowledge, ranging from visual structures (better accuracy in design units and process automation) to role-plays (more realistic understanding of working and living conditions).

Stahl (1993) distinguished between an (ontological) breakdown of understanding and a practical breakdown of action when he analyzed design activity in a lunar habitat design environment. Breakdown in action happens when a technological tool becomes temporarily unavailable (Winograd and Flores, 1986) and when using it creates something unique or uncertain (Schön, 1983). Breakdown in understanding aims to create new knowledge (Ehn, 1988; Fischer et al., 1989). Both situations cause one to step back and think for a moment before making a new move. According to Stahl (1993), when the designer realizes that the last move was not good enough and can make a reasoned decision about how to make the new move, it is a step toward repairing the understanding that led to the breakdown. For a group of learners, it means that the common understanding held by the group is updated (Stahl, 1993).

In the study examples, breakdown of action is more salient because the knowledge expected to be acquired is not about technology but social studies and special education, leading to frequent breakdowns. Despite this, the breakdown illustrated in Example 2 (detailing the windows) required the students to make a reasoned decision about what windows to choose (e.g., discussing the options), which gave them increased understanding of the (social studies) topic. However, this level of understanding was arguably not very deep, as the domain knowledge focused on a single design unit and did not involve related concepts and higher-level abstractions. The task of reconstructing a physical building turned out to be demanding for some of the students because they are not design (architecture) students. More importantly, there were no lectures about the material aspects of abstract domain knowledge, such as class struggle, exploitation, resistance, and conflict. They were incorporated later as part of the role-play (Caruso et al., 2014; Mørch, Mifsud \& Eie, 2019). Furthermore, when computer science is taught as part of another subject (social studies in this case), Example 4 shows that breakdown to solve a practical problem in the primary domain (building a large factory wall) can lead to understanding of a secondary domain concept (nested loops).

\section{Summary and conclusions}

Teachers want their students to acquire domain knowledge according to a shared curriculum, whereas children and students enjoy playing and designing. Many teachers know the importance of leveraging students' previous out-of-school experiences for increased motivation in theoretical classroom activities, but carrying this out in practice is often hard. The aim of the article was to propose ABR as a pedagogical model that combines the practice of domain-specific and generic skills in the same digital learning environment (3D virtual world). The model provides a process for bringing learners from a familiar situation (building on a generic skill such 
as design, collaboration, creativity, engagement, and enthusiasm) to one characterized by surprise, puzzlement, and possible confusion (breakdown). The breakdown provides an opportunity for acquiring new knowledge and for teachers to scaffold when learners repair an unfamiliar situation with the means available. The model was applied as an analytical framework on four learning episodes from two data sets with two virtual worlds in two teacher education programs: scaffolding by the teacher, searching for domain knowledge, and end-user development. We discussed our findings as two dilemmas for closing the educational gap between curricular knowledge and students' interest-driven learning: 1) learning domain knowledge vs. learning technology, and 2) breakdown in action vs. breakdown in understanding. By giving examples of closing the educational gap with ABR and two virtual worlds, we have addressed the special issue theme of transforming educational culture. Resolving the dilemmas requires active participation of teachers and students. The teachers integrate domain knowledge into design activities in the classroom, the students seek out new opportunities for learning with familiar technology, and the technology is flexible and organized as a DODE and organized for teaching according to the ABR model.

Suggestions for further work and implications for practice are as follows. 1) ABR could be put to use in schools as a tool for teachers' lesson planning that extends the work of using ABR in thematic analysis of empirical data. 2) Empirical studies could seek information about students' out-of-school experiences. 3) Further work in technology design could include automated feedback (critiquing) adapted to students' individual needs while building and roleplaying in the two 3D virtual worlds to offload some of the teachers' work in scaffolding design activities in the classroom.

\section{Acknowledgements}

Several colleagues have contributed to the work presented here. In particular Valentina Caruso (virtual ethnography in SL) and Melissa Hartley (online instructor and SL developer), and Louise Mifsud (project leader and researcher) and Siv Eie (researcher in social studies teacher education) who helped organize the MC study. The author is grateful to Department of Education, University of Oslo for seed funding the Second Life research, and Norwegian Agency for International Cooperation and Quality Enhancement in Higher Education (Diku) for funding SMILE (MC in Teacher Education: Developing 21st Century Skills in Social Studies).

\section{References}

Baek, Y., Min, E. \& Yun, S. (2020). Mining educational implications of Minecraft. Computers in the Schools, Vol. 37 No. 1, pp. 1-16,

Bereiter, C. and Scardamalia, M. (2003). "Learning to work creatively with knowledge", In: Corte, E.D., Verschaffel L., Entwistle N. and Merriënboer J.V. (Eds.) Powerful Learning Environments: Unraveling Basic Components and Dimensions, Elsevier Science, Oxford, pp. 73-78.

Binkley, M., Erstad, O., Herman, J., Raizen, S., Ripley, M, Miller-Ricci, M. and Rumble, M. (2012). "Defining twenty-first century skills", In: Griffin P., McGaw B. and Care E. (Eds.) Assessment and Teaching of 21st Century Skills, Springer, Dordrecht, NL, pp. 17-66. 
Boellstorff, T., Nardi, B., Pearce, C. \& Taylor, T.L. (2012). Ethnography and virtual worlds: A handbook of methods. Princeton, NJ: Princeton University Press.

Callaghan, N. (2016). Investigating the role of Minecraft in educational learning environments. Educational Media International, Vol. 53 No. 4, pp. 244-260.

Caruso V., Mørch A.I., Thomassen I., Hartley M. and Ludlow B. (2014). "Practicing collaboration skills through role-play activities in a 3D virtual world", In: Huang R., Kinshuk, Chen NS. (Eds.) The New Development of Technology Enhanced Learning, Springer, Berlin and Heidelberg, pp. 165-184.

Cipollone, M., Schifter, C.C., \& Moffat, R.A. (2014). Minecraft as a Creative Tool: A Case Study. Int. J. Game Based Learn., Vol. 4, pp. 1-14.

Dieterle, E. and Clarke, J. (2007). "Multi-user virtual environments for teaching and learning”, In: Pagani M. (Ed.) Encyclopedia of multimedia technology and networking, Idea Group, Hershey, PA: Idea Group, pp. 1033-1041.

Ehn, P. (1988). Work-oriented design of computer artifacts, Arbetslivscentrum, Stockholm.

Fischer, G. (1994a). "Domain-oriented design environments", Automated Software Engineering, Vol. 1 No. 2, pp. 204-213.

Fischer, G. (1994b). "Turning breakdowns into opportunities for creativity", Knowledge-Based Systems, Vol. 7 No. 4, pp. 221-232.

Fischer, G. and Girgensohn, A. (1990). "End-user modifiability in design environments", In: Proceedings of CHI'90, ACM, New York, NY, pp. 183-192.

Fischer, G., McCall, R. and Mørch, A. (1989). "Janus: Integrating hypertext with a knowledge-based design environment", In: Proceedings of Hypertext'89, ACM, New York, NY, pp. 105-117.

Gregory, S., \& Masters, Y. (2012). Real thinking with virtual hats: A role-playing activity for pre-service teachers in Second Life. Australasian Journal of Educational Technology, Vol. 3 No. 3, pp. 420-440.

Hoadley, C. (2002). "Creating context: Design-based research in creating and understanding CSCL", In: Stahl G (Ed.) Proc. CSCL 2002, Lawrence Erlbaum Associates, Mahwah, NJ, pp. 453-462.

Jordan, B., \& Henderson, A. (1995). Interaction analysis: Foundation and practice. Journal of the Learning Sciences, Vol. 4 No. 1, pp. 39-103.

Lemke, J. (1990). Talking science: Language, learning, and values, Ablex, Norwood, NJ.

Muir, T., Allen, J. M., Rayner, C. S., \& Cleland, B. (2013). Preparing pre-service teachers for classroom practice in a virtual world: A pilot study using Second Life. Journal of Interactive Media in Education, Vol. 2013, Art. 3.

Mørch A.I., Caruso V., Hartley M.D. (2017). "End-user development and learning in Second Life: The evolving artifacts framework with application," In Paternò F., Wulf V. (Eds.) New Perspectives in End-User Development, Springer, Cham, Switzerland, pp. 333-358.

Mørch, A.I., Caruso, V., Hartley, M.D. and Ludlow, B.L. (2018). "Creating contexts for collaborative learning in a 3D virtual world for distance education", In Qian Y. (Ed.) Integrating Multi-User Virtual Environments in Modern Classrooms, IGI Global, Hershey, PA, pp. 137-164.

Mørch, A.I., Eie, S. and Mifsud, L. (2018, May 29). "Tradeoffs in combining domainspecific and generic skills' practice in Minecraft in social studies in teacher education", In: Proceedings of CoPDA 2018, Castiglione della Pescaia, Italy, pp. 44-52. Available March 7, 2020 from http://ceur-ws.org/Vol-2101/ 
Mørch, A.I., Mifsud, L. and Eie, S. (2019). "Developing a model of collaborative learning with Minecraft for social studies classrooms using role-play theory and practice", In: Proceedings of CSCL 2019, Vol. 1, International Society of the Learning Sciences. Lyon, France, pp. 272-279.

Mørch A.I., Murad H., Herstad J., Seibt S. and Kjelling M. (2019). "Material conditions of collaborative knowledge construction: The case of Monoplant", In: Cerratto Pargman T. and Jahnke I. (Eds.), Emergent Practices and Material Conditions in Learning and Teaching with Technologies, Springer, Cham, pp. 147-162.

Nebel, S., Schneider, S., and Rey, G.D. (2015). Mining learning and crafting scientific experiments: A literature review on the use of Minecraft in education and research. Educational Technology \& Society, Vol. 19 No. 2, pp. 355-366.

Norwegian Media Authority (2020). Children and Media 2020. On gaming and spending money in computer games. White paper no. 3. Medietilsynet, Fredrikstad, Norway.

Resnick, L.B. (1987). "Learning in school and out", Educational Researcher, Vol. 16 No. 9, pp. 13-20.

Resnick, M. (2017). Lifelong Kindergarten: Cultivating Creativity through Projects, Passions, Peers, and Play, MIT Press, Cambridge, MA.

Resnick, M., Maloney, J., Monroy-Hernández, A., Rusk, N., Eastmond, E., Brennan, K., Millner, A., Rosenbaum, E., Silver, J., Silverman, B. and Kafai, Y. (2009). "Scratch: Programming for all", Communications in ACM, Vol. 52 No. 11, pp. $60-67$.

Schön, D.A. (1983). The reflective practitioner: How professionals think in action, Basic Books, New York, NY.

Schaaf, R. and Mohan, N. (2014). Making school a game worth playing: Digital games in the classroom, Corwin, Thousand Oaks, CA.

Stahl, G. (1993). Interpretation in design: The problem of tacit and explicit understanding in computer support of cooperative design. Ph.D. thesis, Department of Computer Science, University of Colorado, Boulder, CO.

Vasileiou, V. and Paraskeva, F. (2010). Teaching role-playing instruction in Second Life: An exploratory study. Journal of Information, Information Technology

Vygotsky, L.S. (1986). "The development of scientific concepts in childhood: The design of a working hypothesis", In: Vygotsky L. and Kozulin A. (Eds.), Thought and Language. MIT Press, Cambridge, MA, pp. 146-209.

Winograd, T. and Flores, F. (1986). Understanding computers and cognition: A new foundation for design, Ablex, Norwood, NJ. 